\title{
La reparación: una aproximación a su historia, presente y prospectivas ${ }^{1}$
}

\author{
Juliana Nanclares \\ Márquez ${ }^{2}$
}

Ariel Humberto
Gómez Gómez

\section{juliana.nanclaresma@unaula.edu.corariel.gomezgo@unaula.edu.co}

\author{
Artículo de la Revista Civilizar Ciencias Sociales \\ y Humanas de la Universidad Sergio Arboleda
}

\begin{abstract}
${ }^{1}$ El presente escrito es resultado del proyecto de investigación 'El proceso judicial de restitución de tierras en el Urabá antioqueño' que se desarrolla en la Universidad Autónoma Latinoamericana en asocio con el Instituto Popular de Capacitación, convocatoria 2015 - 1. El proyecto es financiado por estas dos entidades.

2 Docente investigadora de la Maestría en Derecho Administrativo y. Coordinadora de la línea de investigación: Responsabilidad extracontractual del Estado, Universidad Autónoma Latinoamericana. Correo electrónico: juliana.nanclaresma@unaula.edu.co ${ }^{3}$ Docente investigador de la Maestría en Educación y Derechos Humanos y Coordinador de la línea de investigación: Conflictos, transiciones y construcción de paz, Universidad Autónoma Latinoamericana. Correo electrónico: ariel.gomezgo@unaula.edu.co

${ }^{4}$ Fuente original en Nanclares, J., \& Gómez, A. (2017). La reparación: una aproximación a su historia, presente y prospectivas. Civilizar Ciencias Sociales y Humanas, 17(33), 59-80. doi: 10.22518/16578953.899. Agradecimientos especiales a Juliana Nanclares y Ariel Gómez, así como Yadira Caballero directora de publicaciones de la Universidad Sergio Arboleda, por permitirnos publicar este artículo tan relevante para la temática del número. Esta nota al fue agregada por el Equipo Editorial de la revista Trans-pasando Fronteras.
\end{abstract}




\section{Resumen}

El presente escrito desarrolla un estudio del concepto de reparación del daño desde el punto de vista de la doctrina a través del método de análisis documental. En este orden de ideas, a partir de los diversos significados de esta noción se busca demostrar que es necesario conocer con qué sentido se ha utilizado el término reparación para entender su alcance en el contexto específico. Ala par se propone una definición que se aproxime a los requerimientos actuales. Se concluye que la forma y ámbito de aplicación en el cual se haya empleado determinarán su alcance, en especial, para el operador judicial a quien le corresponde aplicar el derecho.

Palabras clave: Reparación; Reparación integral; Noción amplia de reparación; Reparación transformadora; Reparación en programas de cubrimiento masivo; Reparación en contexto; Responsabilidad extracontractual del Estado; Daño. 


\title{
The Reparation: an approach to its history, present and future
}

\begin{abstract}
This paper develops a study of the concept of reparation of damage from the point of view of the doctrine through the method of documentary analysis. In this order of ideas, from the various meanings of this notion, it is sought to demonstrate that it is necessary to know in what sense the term reparation has been used to understand its scope in the specific context. At the same time, a definition that approximates the current requirements is proposed. It is concluded that the form and scope of application in which it has been used will determine its scope, especially for the judicial operator to whom the right applies who applies law.
\end{abstract}

Keywords: Reparation; Integral reparation; Comprehensive notion of reparation; Transformative reparation; Reparation in massive coverage programs; Reparation in context; Extracontractual liability of the State; Damage. 


\section{Introducción}

La reparación es un asunto que hoy en día adquiere especial relevancia, como quiera que es la primera función de la responsabilidad, pues con base en la definición de ser responsable expuesta por Visintini (2015), significa estar obligado a resarcir el daño. En la actualidad, la reparación asume diversos significados de acuerdo al contexto en el cual sea utilizada. Por tal razón, resulta oportuno conocerlos para establecer su alcance en el ordenamiento jurídico colombiano.

En un Estado social de derecho como Colombia, donde quienes lo integran deben tener certeza sobre las consecuencias de sus actos, el sentido de la reparación es importante; de un lado, para quien sufre un daño y le debe ser reparado, y de otro, para quien tiene el deber de reparar. La envergadura de esta reflexión cobra especial interés para Colombia en el marco de las discusiones actuales sobre la restitución de tierras, donde el tema de la reparación es uno de los componentes medulares de la Ley 1448 de 2011.

El presente trabajo se desarrolló a partir del método de análisis documental. Se inició con el análisis jurídico descriptivo de la noción de reparación el cual incluye una mirada desde su perspectiva histórica, lingüística y doctrinal; luego se estudió dicho concepto con el adjetivo integral y se indagó su significado en el derecho contemporáneo. Finalmente, en el escrito se propone una definición que, en la medida de lo posible, se aproxime a los requerimientos actuales. El ámbito específico de análisis se circunscribió al significado de la reparación en el contexto colombiano donde confluye normativa que consagra programas masivos de reparaciones concebidos en desarrollo de políticas públicas ${ }^{5}$, mecanismos de justicia transicional6, con el control judicial por parte de la Jurisdicción de lo contenciosoadministrativo de la responsabilidad extracontractual del Estado. 


\section{Antecedentes del concepto de reparación}

En sus inicios, desde el Código de Hammurabi (siglo XVII a. C.) las nociones de responsabilidad civil y penal estaban fusionadas y se confundían la una con la otra. Este código es un claro antecedente histórico de las tablas y baremos que existen en la actualidad (Velásquez, 2009). El Código de Hamurabi estableció la Ley del Talión, pero además, también contempló la posibilidad de la compensación en dinero de los daños diferentes a los atentados contra la persona, pues tradicionalmente el daño a la persona se consideró irresarcible (Koteich, 2006).

En el derecho hebreo, el libro del Éxodo contiene, además del Decálogo, leyes que muestran cómo se reparaban los daños para la época. En cuanto los daños a las personas, el Éxodo realizó una compilación casuística, de acuerdo con los casos más comunes en los que se causaran perjuicios, donde se establecía la obligación de indemnizar mediante penas corporales y pecuniarias. Los delitos menos graves se regían por la Ley del Talión, constituyéndose un límite a la indemnización (Koteich, 2006).

En el derecho romano, se confundieron los conceptos de pena y de reparación. Muestra de ello es que a pesar de existir acciones que tenían como fin principal la reparación, y otras con un propósito esencialmente penal, esa distinción se tornó difusa cuando posteriormente se adoptaron las acciones mixtas que buscaban tanto la imposición de una pena como la indemnización. Aunado a lo anterior, está el hecho que el derecho romano siempre conservó el método casuístico (Viney, 2007). Precisamente, como

${ }^{5}$ Ley 1448 de 2011

${ }^{6}$ Lay 975 de 2005 
resultado del uso de este método, los romanos no establecieron un principio general de responsabilidad, ni se cuestionaron por su fundamento. Por ende, no lograron hacer de la condena civil lo que es hoy: una indemnización. El legislador romano describió los delitos de los cuales surgía la obligación de reparar, y los decidió caso por caso; posteriormente, los jurisconsultos se percataron que este mecanismo era insuficiente. No obstante, solo extendieron la aplicación de los textos legales menos concretos a otros casos, sin lograr la consagración de una regla de carácter general (Mazeaud, Mazeaud, \& Tunc, 1977).

La Ley del Talión se aplicó como un mecanismo según el cual la víctima no podía buscar más reparación que la equivalente al daño padecido. En principio, las consecuencias consistían en la muerte y sufrimiento o mutilaciones físicas que infligía la víctima o su padre al causante del daño. Más tarde, en la Ley de las XII Tablas se hizo un tránsito de la composición facultativa o voluntaria a la composición obligatoria. En la composición voluntaria, el sujeto podía, a elección, devolver el mal sufrido o solicitar un resarcimiento monetario (Jalil, 2013). La composición obligatoria se conoció como pena privada (poena) y reparación. La pena era una suma de dinero que pagaba quien ocasionaba el daño en sustitución de las acciones sobre su cuerpo. La legislación decenviral, precedente de la Ley Aquilia, contenía una tipificación taxativa de conductas que daban lugar a la respectiva acción de reparación (Velásquez, 2009).

La persecución de los delitos públicos era de interés de la ciudad y por ende de exclusivo resorte del Estado, mientras que el castigo de los delitos privados era buscado por las víctimas en su propio provecho y, en consecuencia, el perjudicado tenía una acción privada para obtener su reparación. Por dicha razón, la obligación de resarcimiento que surgía del delito se extinguía con la 
muerte del ofensor debido a que la misma no tenía función compensatoria (Barros, 2007). En la Instituta de Justiniano se consagraron cuatro delitos privados: el furtum (hurto), la rapiña, la iniuria y, el damnum iniuria datum. Delitos como el furtum establecían a modo de reparación el valor del cuádruple o del duplo del perjuicio, según la modalidad del hurto (manifiesto o no manifiesto); estos valores correspondían únicamente al valor de la pena, pues además se contaba con la posibilidad de perseguir la cosa. En el delito de rapiña, el agresor estaba obligado a restituir el cuádruplo de la cosa; dicho valor incluía la persecución de la cosa de tal suerte que la pena obedecía al triplo (Molinas, 1889).

El primer capítulo de la Lex Aquilia frente al damnum iniuria datum (daño al patrimonio), consagró la obligación de reparar los daños causados a los dueños de esclavos y de animales que pastan en rebaños. En esos casos determinó como valor de reparación la mayor tasación que hubiese tenido la cosa en ese año. En el título II del Digesto, comentarios a la Ley Aquilia, se dispuso que el cómputo del año se debía realizar hacia atrás a partir del suceso que generó el daño; disposición que contenía la estimación del daño causado. La acción otorgada por la ley era de carácter penal, pues generaba una obligación que iba más allá del daño causado y no se transmitía a los herederos. Asimismo, la Lex Aquilia determinó que no solo se estaba obligado al pago de la estimación del valor de la cosa, sino a cualquier otro daño que se hubiere causado.

En el tercer capítulo de la Lex Aquilia, se contempló de una manera más general la obligación de reparar los daños causados a animales, diferentes a los consagrados en el primer capítulo; a los esclavos en caso diferente de muerte, y a todo tipo de cosas inanimadas. También se estableció que por cualquier otro daño causado por dolo o culpa nacía la obligación de reparar y se im- 
plantó como monto de la indemnización el mayor precio de la cosa en los últimos treinta días. De otra parte, cuando se caían objetos inanimados debía pagarse diez áureos, mientras que si se arrojaban, correspondía reparar el doble del daño realmente causado. Si en estos eventos fallecía una persona libre, se entregaban cincuenta áureos los cuales no hacían referencia a los daños inferidos a sus cosas, sino a los causados a su cuerpo; si quedaba vivo, el juez reconocía equitativamente la reparación, en la que tenía en cuenta los gastos médicos y las labores que no pudo ni podría realizar la persona, en atención al daño padecido. Sin embargo, se resalta que no se hacía la estimación de las cicatrices o la deformidad, puesto que el cuerpo del hombre libre no admitía apreciación en dinero.

La iniuria, o daño a la integridad física, moral y a la honra de una persona libre, daba lugar a una multa tasada por el juez con base en lo estimado por el injuriado o lo que le hubiese parecido al juez (Molinas, 1889). La valoración de la condena, que consistía en una pena privada, correspondía a una suma de dinero según lo equitativo y bueno (Sánchez, 2012). Ello indica que se trataba más bien de una pena de carácter punitivo que resarcitorio

El libro noveno del Digesto desarrolló principalmente el daño injustificado. Ulpiano, en los cometarios al Edicto, Libro XVIII del Libro Noveno del Digesto, consagró que si un cuadrúpedo causaba un daño, surgía una acción de las XII Tablas que consistía en dar aquello que causó el daño (el animal) o el importe del daño. En los comentarios de Gayo al Edicto Provincial del Libro VII del Libro Noveno del Digesto, se estableció que si un animal causaba daños a una persona libre, se tendrían en cuenta los gastos de su cura, el trabajo perdido y el que en un futuro perdiera la persona (Molinas, 1889). Dicho libro se fundamentó en un sistema basado en el principio general de la culpa, el cual se complementó con hipó- 
tesis típicas de responsabilidad sin culpa, y cuya finalidad era que el daño no fuera soportado por la víctima (Schipani, 2007). Pese a que en la época clásica Gayo distinguió las acciones penales que solo perseguían la reparación del daño (ut rem tantum consequamur), de aquellas que tenían como finalidad la pena y la reparación (ut rem et poenam), el derecho romano nunca se libró completamente de la idea que la composición era una pena privada (Sarmiento, 2009). Por ende, se puede concluir que a los romanos se les dificultó el desarrollo de una función exclusivamente resarcitoria de la responsabilidad más allá de la retribución debido a que la responsabilidad penal no se desligó en su totalidad de la civil. Lo anterior, a pesar que con el damnun iniura datum comenzó a perfilarse el carácter resarcitorio de la ofensa (Koteich, 2012).

Posteriormente, las Leyes Bárbaras, de las cuales la más conocida es la Ley Sálica, consagraron como reparación tarifas de composición de acuerdo con la naturaleza del daño y con la clase de persona y, en consecuencia, fijaron una sanción denominada wergeld (Viney, 2007). Dichas leyes permitían que la familia de la víctima escogiera alternativamente entre la composición y la vendetta. La función de estos mecanismos era sancionatoria e indemnizatoria. Además, se estableció un carácter colectivo para la reparación, ya que el resarcimiento no solo estaba a cargo de quien causaba el daño, sino en conjunto con sus padres, y no solo se compensaba a la víctima, sino también a sus parientes próximos. Más tarde, en la compilación justinianea, los canonistas eliminaron el concepto de solidaridad familiar para reclamar la indemnización (Velásquez, 2009). El antiguo derecho francés fue influenciado por los textos legales romanos que establecieron la distinción entre acciones penales y acciones reipersecutorias. Los franceses, a diferencia de los romanos, se separaron de la casuística y se concentraron en establecer una regla teórica. Los antiguos autores franceses vieron en la acción 
civil la posibilidad de atribuir un precio a la sangre y a la venganza, por ende, la acción no se transmitía a quienes recogían el patrimonio de la víctima, sino solo a los parientes más cercanos, pues la venganza le pertenecía a la familia (Mazeaud et al., 1977).

En la obra de Domat, se consagró por primera vez el principio general de la responsabilidad civil, que dispuso como consecuencia de todas las clases de obligaciones particulares y de no dañar a nadie, que quienes causaran cualquier daño estaban obligados a repararlo (Viney, 2007). El hecho de establecer una regla general permitió ampliar la noción de perjuicio reparable. Se puede decir que el Código Civil francés de 1804, a pesar de no instituir un capítulo dedicado a la responsabilidad, sí consagró el principio general de la responsabilidad civil enunciado en el Artículo 1382: "Tout fait quelconque de I'homme, qui cause à autrui un dommage, oblige celui par la faute duquel il est arrivé à le réparer"7, y vinculó la reparación del daño al valor del perjuicio sufrido, es decir, cuantificó la condena en función de la medida del perjuicio (Viney, 2007). Para finalizar, actualmente y desde los inicios del Siglo XX, el seguro de responsabilidad civil incide considerablemente en la reparación de las víctimas. Dada su presencia, se amplió la categoría de daños reparables, lo que permitió un acercamiento a la reparación integral. Luego de esta breve reseña histórica sobre la reparación, se observa cómo desde sus inicios se concibe como consecuencia de la responsabilidad; responsabilidad civil y penal que desde el Código de Hammurabi estuvo fusionada. Es por tal razón que las primeras expresiones se encuentran en la Ley del Talión, luego pasan por la compensación de los daños diferentes a la persona, posteriormente comprenden penas corporales y pecuniarias, para finalmente reflejarse en un principio general.

\footnotetext{
${ }^{7}$ Traducción libre: Todo hecho de cualquier hombre que cause a otro un daño, obliga a la persona por cuya culpa ha ocurrido, a repararlo (Código civil Francés).
} 


\section{La reparación: aproximación conceptual}

El Diccionario de la lengua española (2014) define así la palabra reparación:

Del lat. tardío reparatio, -ōnis 'restablecimiento, renovación'. Acción y efecto de reparar algo roto o estropeado. Desagravio, satisfacción completa de una ofensa, daño o injuria.

Y así, la palabra reparar:

Del lat. reparāre. Arreglar algo que está roto o estropeado; enmendar, corregir o remediar; desagraviar, satisfacer al ofendido; remediar o precaver un daño o perjuicio

\section{Noción de reparación de acuerdo con diversos autores}

Para Fisher (1928) reparar es el deber del victimario de generar una nueva cadena de hechos que acerque, en la mayor medida posible, la realidad dañada a la que existiría de no haberse ocasionado el perjuicio.

Se puede decir que Alpa (2006), y Mazeaud et al. (1977), realizan un acercamiento similar en el sentido de considerar que reparar es reponer las cosas al estado anterior y adoptar las medidas necesarias para situar al demandante en las mismas condiciones en que estaba antes del suceso dañoso. Otros autores plantean la noción desde el vínculo obligacional: para De Cupis (1975), la reparación del daño se concreta en el deber de resarcir, impuesto al responsable de un daño causado contra ius ${ }^{8}$, encaminado a la reintegración del interés lesionado. En textos recientes, Henao (2015) señala que es "La manera como el responsable cumple la obligación de reparar 
asegurando a la víctima el retorno al status quo ante al acaecimiento del daño" (pp. 286). Cortés (2009) plantea que la reparación responde a la necesidad de devolver a la víctima lo que ha perdido. Finalmente, Solarte (2009) enuncia que la obligación de reparar también se ha entendido como una sanción jurídica a la violación de un deber jurídico general o específico en cuya ejecución se ha ocasionado un daño. En este sentido, la reparación busca acercase a la situación que existiría de no haber acaecido el daño, es decir, crear un estado de cosas que de momento no existe.

Por otra parte, Ghersi (1995) considera que los términos reparar e indemnizar, no son sinónimos: interpreta indemnizar como resarcir un daño, perjuicio o agravios; mientras que reparar es componer o enmendar el daño que ha sufrido una cosa, como también evitar o remediar el acaecimiento de un perjuicio. De otra parte, Velásquez (2009) señala que las palabras con las que se relaciona el concepto "reparación de la víctima" (reparar, restituir, indemnizar y compensar), son términos que no siempre tienen el mismo significado.

Restituir expresa situar al perjudicado nuevamente en dominio de lo que le pertenece y cuando ello no es posible, debemos acudir a la compensación. En la actualidad, el término más comúnmente empleado es indemnizar, y se aplica en el sentido de "dejar sin daño".

En las definiciones doctrinales referenciadas, se encuentran varios puntos comunes: reparar es volver las cosas al estado anterior, es decir, ubicar al perjudicado en la situación anterior o más próxima, previa al acaecimiento del daño; este argumento se concreta en el deber de resarcir impuesto al responsable de un daño causado contra derecho, el cual se encamina a la reintegración del interés lesionado.

${ }^{8}$ Contrario a derecho 
Como puntos de encuentro, y para el análisis objeto de este escrito, se observa que la reparación surge de un vínculo obligacional que se origina del acaecimiento de un daño que le es imputable a quien es encontrado responsable.

\section{La reparación integral: aproximación conceptual}

Alterini y López Cabana (1995) plantean que la reparación integral consiste en una aspiración de máxima que indica que debe repararse todo el daño jurídicamente resarcible. Claro está que como no siempre es posible, el ordenamiento jurídico permite resarcir los daños con relativa plenitud.

Para Viney y Jourdain (2001), la reparación integral tiene como finalidad alcanzar la más perfecta equivalencia entre el daño padecido y su reparación, de tal forma que quien sufre el perjuicio quede en la situación más parecida a la que se encontraba si el hecho dañoso no hubiese acaecido.

Navia (2007) retoma el concepto de la Corte de Casación francesa, en el que la reparación integral es el restablecimiento, tan exacto como sea posible, del equilibrio destruido por el daño, al ubicar a la víctima en una situación equivalente a la que se encontraba si el daño no hubiere ocurrido.

Barros (2007) expone que este concepto ha sido entendido como que todo daño debe ser reparado en toda su extensión. En este sentido, la reparación integral tiene por objeto poner al demandante en la situación que se encontraba de no haber padecido el perjuicio ocasionado por el demandado. 
En concordancia con Barros, Gual (2009) infiere que la reparación integral es restablecer a quien ha padecido un perjuicio, en la medida de lo posible, a la condición que existía al momento previo de su acaecimiento. Así mismo, Solarte (2009) expone que la reparación del daño debe ser integral. Para tal efecto, la finalidad del resarcimiento es situar a la víctima en el estado que se encontraría si el daño no hubiese ocurrido.

En la actualidad, en el derecho comparado y en la doctrina, existen controversias en relación con la generalidad y la vigencia del principio de reparación integral, ya que tiene varias excepciones a su aplicación, tales como que solo opera frente a los daños patrimoniales, a los límites legales y convencionales en relación con el monto de las indemnizaciones, las tarifas o baremos y, a la posibilidad de que la víctima obtenga diversas indemnizaciones provenientes de distintas fuentes. Solarte (2009) concluye que un principio tan lleno de excepciones no satisface la característica de inalterabilidad o estabilidad propia de los principios.

Cortés (2009) plantea que la reparación integral indica que todo el daño debe ser resarcido; su noción es objeto de innumerables críticas en cuanto al resarcimiento del daño a la persona. Ante ello, él afirma que se presenta un error conceptual pues la reparación del daño habla de la extensión de la misma, pero solo en cuanto a los daños que se consideran resarcibles, por ende, el llamado principio de la reparación integral no es un criterio de selección para delimitar qué perjuicios son merecedores de protección. Para Velásquez (2009), la reparación integral debe ser entendida como un principio de aspiración, pues si bien se debe indemnizar todo el daño causado y nada más que ese daño, desde un punto de vista ontológico no siempre es viable. Por tal motivo apunta que la reparación debe tender a ser integral en la medida de lo humanamente posible. 
Gil (2011) expone que "la reparación integral supone el desagravio y la satisfacción completa, total y global del daño antijurídico irrogado" (p.123). Por tal razón, le impone al juez

La obligación de que, con apoyo en los cánones y principios constitucionales, establezca una 'justa y correcta' medición del daño ocasionado, de tal forma que opere su resarcimiento o indemnización plena, sin que ello suponga, de otro lado, un enriquecimiento injustificado para la víctima (Sentencia del 14 de septimebre de 2011. Radicación número: 05001-23-31-000-2007-00139-01(38222)).

Esta tarea, de suyo, implica que el juez realice una valoración detallada de cada uno de los perjuicios sufridos por la víctima para proceder a su reparación.

Para Koteich (2012), la reparación integral "Impone considerar más que las simples proyecciones patrimoniales o materiales del hecho ilícito, es decir, tomar a la persona de la víctima como una compleja realidad biológica, social y espiritual" (p. 18).

Visintini (2015) explica que en el Derecho italiano la reparación integral del daño, llamado principio de la equivalencia entre el daño y la reparación, consiste en "que todo daño que ocasione una pérdida patrimonial o frustración de una ganancia debe ser resarcido" (p.291), noción limitada a la órbita patrimonial del perjudicado. Principio que en Italia no encuentra aplicación en el evento del resarcimiento del daño no patrimonial donde predomina el uso de la valoración equitativa.

En suma, pareciera que hablar de reparación implica hablar de reparación integral. No obstante, lo anterior, si bien reparar lleva en sí mismo el hecho de situar al perjudicado en el estado anterior o más 
próximo al que se encontraba antes del daño, el adjetivo integral insta a un comportamiento más exigente por parte de quien tiene la obligación de resarcir el daño, así como por parte del juez. Dicha exigencia es precisamente hacerlo en su totalidad, no solo desde el punto de vista del quantum del perjuicio, sino en atención a la tipología de daños resarcibles. De lo anterior se observa que, al margen de la cualificación como integral de la reparación, la misma continúa como la consecuencia derivada de la obligación de resarcir el daño por parte de quien es declarado responsable, solo que en virtud de la integralidad, se le exhorta a que la realice en su totalidad.

\section{Prospectivas del concepto de reparación integral: desde el derecho contemporáneo hasta la actualidad}

En la actualidad el concepto de reparación se ha redefinido debido a que hoy ocurren daños de gran magnitud, no solo en cuanto al número de víctimas, sino además en cuanto a la gravedad del perjuicio. A continuación, se hará referencia a la redefinición de este concepto en el ámbito de la responsabilidad extracontractual del Estado.

En el escenario internacional se encuentran diferentes perspectivas. Algunas adoptan una noción amplia de reparación, como lo hace la Corte Interamericana de Derechos Humanos (en adelante CorteIDH), otras proponen que la reparación trascienda el restablecimiento del derecho e incida en las políticas públicas (este pensamiento es poco compartido, y lo expondremos más adelante). También se encuentra la visión de los programas administrativos de reparación como una respuesta real a la justicia transicional fruto de los altos costos en los que incurriría un Estado en el caso de acudir a la reparación individual y, finalmente, está la reparación en contexto. 


\section{Noción amplia de reparación}

Para la CortelDH, intérprete legítimo de la Convención Americana sobre Derechos Humanos (Pacto de San José), la reparación es "el término genérico que comprende las diferentes formas cómo un Estado puede hacer frente a la responsabilidad internacional en que ha incurrido" (tal como se expone en el caso Garrido y Baigorria Vs. Argentina, 1998, p.11). La reparación es consecuencia de la violación por parte de un Estado de un compromiso internacional, por tal razón, las medidas resarcitorias serán acordes con el Derecho Internacional ${ }^{11}$, en otras palabras, al derecho de gentes. Este carácter universal de la obligación de reparar otorga relevancia a la jurisprudencia de la CortelDH, la cual desarrolla su contenido, señalando que la reparación del daño es la plena restitución (restitutio in integrum); según Andreu et al. (2014) ${ }^{10}$, el restablecimiento de la víctima a la situación anterior y la indemnización como compensación de los daños patrimoniales y extrapatrimoniales. En este orden de ideas, la naturaleza y características de las violaciones determinan las formas de reparar, es decir, la naturaleza del daño padecido debe guardar correlación con las medidas adoptadas para proteger bienes jurídicamente tutelados por la Convención Americana sobre Derechos Humanos.

La CortelDH (2005) afirma claramente que para que exista reparación es necesario que la misma ocurra con justicia, oportunidad y suficiencia, es decir, administrada por un órgano legítimo, de manera diligente y apropiada, de acuerdo con el daño

\footnotetext{
${ }^{9}$ En relación con el trámite de la reparación, ver Olando García (2013)

10 Las reparaciones son medidas que tienden a hacer desaparecer los efectos de las violaciones cometidas. Su naturaleza y su monto dependen de las características de la violación y del daño ocasionado en los planos material e inmaterial. (Caso Acevedo Jaramillo y otros Vs. Perú, 2006).
} 
padecido. Adicionalmente, considera que el Artículo 63 de la Convención Americana sobre Derechos Humanos contempla las finalidades preventivas y resarcitorias de la reparación.

La Comisión Interamericana de Derechos Humanos (2013) en adelante $\mathrm{CIDH}$-, sostiene que la eficacia debe guiar la implementación de las medidas de reparación y orientación, que comprenden la participación de las víctimas en su diseño, ejecución y atendiendo sus necesidades y expectativas, toda vez que en estos casos la reparación debe ser diferencial, preferencial e integral. Medidas que no pueden confundirse con la asistencia humanitaria y satisfacción de otras necesidades por parte del Estado. De esta manera las medidas logran un efecto reparador.

Hemos observado que las mencionadas conceptualizaciones adoptan una noción amplia de reparación, entendida como la forma en que un Estado hace frente a la responsabilidad en que ha incurrido al restablecer a la persona que sufre el daño a la condición anterior de no haberse presentado el mismo.

En el escenario latinoamericano existe otra propuesta en torno a la reparación denominada 'reparaciones transformadoras', cuya intención es ir más allá de su función restitutiva.

\section{Reparación transformadora}

Como lo exponen Uprimny y Saffon (2009), la perspectiva restitutiva de la reparación integral se queda corta, limitada, es poco realista y demasiado exigente cuando se pretende resarcir a individuos pertenecientes a sociedades que vivencian una profunda crisis política y humanitaria y, que ya estaban en condiciones de desigualdad antes de padecer el daño. 
Por consiguiente y para contribuir al resarcimiento del daño, la verdad, las iniciativas de justicia y las garantías de no repetición son elementos que hacen parte de lo que hoy se entiende por reparación, ampliando entonces la comprensión del concepto hacia una perspectiva centrada en las víctimas y que involucre su participación.

Para superar la limitación de un enfoque eminentemente restitutivo de las reparaciones, Uprimny y Saffon (2009) desarrollan las Ilamadas 'reparaciones transformadoras', una alternativa de justicia correctiva que busca una transformación democrática de la sociedad. Las 'reparaciones transformadoras' pretenden ir más allá de la simple restitución, puesto que no solo deben enfrentar el daño padecido, sino también las condiciones que permitieron su acaecimiento y continuidad, para prevenir futuros daños.

Desde este punto de vista la reparación podría ser comprendida como un mecanismo de justicia distributiva que propenda por la inclusión de las víctimas al proyecto político común. Esta propuesta tiene como fin último la articulación del resarcimiento de los perjuicios de las víctimas, con la tarea igualmente importante de construir una sociedad democrática más equitativa e incluyente.

La CortelDH (2009) expone este concepto en el Caso González y otras (denominado "Campo Algodonero") V.S. México:

450. La Corte recuerda que el concepto de "reparación integral" (restitutio in integrum) implica el restablecimiento de la situación anterior y la eliminación de los efectos que la violación produjo, así como una indemnización como compensación por los daños causados. Sin embargo, teniendo en cuenta la situación de discriminación estructural en la que se enmarcan los hechos ocurridos en el presente caso y que fue reconocida por el Estado (su- 
pra párrs. 129 y 152), las reparaciones deben tener una vocación transformadora de dicha situación, de tal forma que las mismas tengan un efecto no solo restitutivo sino también correctivo. En este sentido, no es admisible una restitución a la misma situación estructural de violencia y discriminación. Del mismo modo, la Corte recuerda que la naturaleza y monto de la reparación ordenada dependen del daño ocasionado en los planos tanto material como inmaterial. Las reparaciones no pueden implicar ni enriquecimiento ni empobrecimiento para la víctima o sus familiares, y deben guardar relación directa con las violaciones declaradas. Una o más medidas pueden reparar un daño específico sin que éstas se consideren una doble reparación (p. 114).

Si bien destacamos que esta redefinición de la reparación tiene un propósito loable, resulta necesario un análisis de su consagración en el ordenamiento jurídico colombiano, para luego establecer las posibles consecuencias que se derivarían de su aplicación, así como, de ser acogida por los jueces en Colombia, su alcance en las sentencias que conlleven el reconocimiento de la pretensión de reparación. La única normativa que consagra de alguna manera la noción transformación, es el Artículo 25 (Derecho a la reparación integral) de la Ley 1448 de 2011, que dispone:

Las víctimas tienen derecho a ser reparadas de manera adecuada, diferenciada, transformadora y efectiva por el daño que han sufrido como consecuencia de las violaciones de que trata el artículo 30 de la presente Ley.

La reparación comprende las medidas de restitución, indemnización, rehabilitación, satisfacción y garantías de no repetición, en sus dimensiones individual, colectiva, material, moral y sim- 
bólica. Cada una de estas medidas será implementada a favor de la víctima dependiendo de la vulneración en sus derechos y las características del hecho victimizante.

Parágrafo 1.- Las medidas de asistencia adicionales consagradas en la presente ley propenden por la reparación integral de las víctimas y se consideran complementarias a las medidas de reparación al aumentar su impacto en la población beneficiaria. Por lo tanto, se reconoce el efecto reparador de las medidas de asistencia establecidas en la presente ley,en la medida en que consagren acciones adicionales a las desarrolladas en el marco de la política social del Gobierno Nacional para la población vulnerable, incluyan criterios de priorización, así como características y elementos particulares que responden a las necesidades específicas de las víctimas.

No obstante, este efecto reparador de las medidas de asistencia, estas no sustituyen o reemplazan a las medidas de reparación. Por lo tanto, el costo o las erogaciones en las que incurra el Estado en la prestación de los servicios de asistencia, en ningún caso serán descontados de la indemnización administrativa o judicial a que tienen derecho las víctimas.

Parágrafo 2.- La ayuda humanitaria definida en los términos de la presente ley no constituye reparación y en consecuencia tampoco será descontada de la indemnización administrativa o judicial a que tienen derecho las víctimas.

De la exposición de motivos de esta ley, se desprende que los servicios sociales a cargo del Gobierno dispuestos en favor de las víctimas poseen un designio e intencionalidad distinta y, además, obedecen a títulos jurídicos diferentes. Por tal razón, la palabra transformadora consagrada en el Artículo citado, debe entender- 
se en el sentido dado por el Diccionario de la lengua española (2014): "que transforma"; transformar: "hacer cambiar de forma a alguien o algo", meta que se alcanza con las diferentes formas de reparación establecidas en el ordenamiento jurídico colombiano, en atención a la entidad del perjuicio, sin que sea necesario que el juez exceda su competencia.

Los artículos 5, 21 y 28 del Decreto - Ley 4633 de 2011, hacen referencia al término "transformador". Se observa que esta expresión se utiliza con un significado general, pues su alcance se limita al restablecimiento de los derechos vulnerados y a la implementación de las medidas de indemnización, rehabilitación, satisfacción y garantías de no repetición.

Artículo 5.- Reparación integral y restablecimiento del equilibrio y la armonía de los pueblos indígenas. El concepto de reparación integral para los pueblos indígenas, individual y colectivamente considerados, se entenderá como el restablecimiento del equilibrio y la armonía de los pueblos, vulnerados históricamente en sus dimensiones material e inmaterial.

$[\ldots]$

Dicho restablecimiento se entenderá como un proceso que incorpora un conjunto de medidas y acciones transformadoras, justas y adecuadas dirigidas a fortalecer la autodeterminación y las instituciones propias, garantizar el goce efectivo de los derechos territoriales y el restablecimiento de los mismos, en caso de que hayan sido vulnerados, e implementar medidas de indemnización, rehabilitación, satisfacción y garantías de no repetición. Los derechos a la justicia y a la verdad hacen parte de la reparación integral de las víctimas. 
Artículo 21.- Distinción y autonomía de las medidas individuales y colectivas de reparación. Los pueblos y comunidades indígenas como sujetos colectivos y sus integrantes individualmente considerados tienen derecho a ser reparados de manera integral, adecuada, diferenciada, transformadora y efectiva. La ayuda y asistencia humanitaria, así como la prestación de los servicios sociales del Estado, no constituyen medidas de reparación integral.

El acceso prioritario, especial y preferente de las víctimas a los servicios sociales del Estado, conforme a la Ley 418 de 1997, hace parte de la asistencia humanitaria. En consecuencia, el valor de estas medidas no podrá descontarse del valor de la reparación integral, administrativa o judicial, a la que tienen derecho las víctimas.

De manera excepcional, cuando se establezcan específicamente prestaciones sociales para las víctimas que sean notoriamente superiores a las previstas en la política social general, que respondan a las características y elementos particulares de las necesidades específicas de las víctimas individual y colectivamente consideradas, y su otorgamiento se encuentre acompañado de formas de reparación simbólica y del reconocimiento del daño, estas podrán considerarse como prestaciones complementarias a las medidas generales de reparación integral.

Artículo 28.- Reparación transformadora. El Estado garantizará la reparación integral para los pueblos indígenas con carácter transformador. La reparación integral, en tanto transformadora, no se limita al resarcimiento del daño material y espiritual, o al restablecimiento de la situación anterior al hecho victimizante, sino que también se verá complementada por acciones que contribuyan a la eliminación de los esquemas de discriminación y marginación que pudieron ser la causa de los hechos victimizantes. 
En el Decreto 4634 de 2011, también se emplean los términos "transformadora" y "reparación transformadora" en sus artículos $17,23,33$ y 46.

Artículo 17.- Reparación integral y restablecimiento del equilibrio y la armonía del pueblo Rom. El concepto de reparación integral para el pueblo Rom y sus miembros individualmente considerados, se entenderá como el restablecimiento del equilibrio y la armonía de este pueblo, vulnerados históricamente en sus dimensiones material e inmaterial. De la dimensión inmaterial forman parte los fundamentos espirituales, culturales, ancestrales y cosmogónicos, entre otros.

Dicho restablecimiento se entenderá como un proceso que incorpora un conjunto de medidas y acciones transformadoras, justas y adecuadas dirigidas a fortalecer la autodeterminación y las instituciones propias, garantizar el goce efectivo de todos los derechos y el restablecimiento de los mismos en caso de que hayan sido vulnerados e implementar medidas de indemnización, rehabilitación, satisfacción y garantías de no repetición.

\section{$[\ldots]$}

Artículo 23.- Distinción y autonomía de las medidas individuales y colectivas de reparación. Las víctimas individuales y colectivas pertenecientes al pueblo Rom o Gitano tienen derecho a ser reparadas de manera integral, adecuada, diferenciada, transformadora y efectiva. La ayuda y asistencia humanitaria, así como la prestación de los servicios sociales del Estado, no constituyen medidas de reparación integral. El acceso prioritario, especial y preferente de las víctimas a los servicios sociales del Estado, conforme a la Ley 418 de 1997, hace parte de la asistencia humanitaria. 
En consecuencia, el valor de estas medidas no podrá descontarse del valor de la reparación integral, administrativa o judicial, a la que tienen derecho las víctimas.

De manera excepcional, cuando se establezcan específicamente prestaciones sociales para las víctimas que sean notoriamente superiores a las previstas en la política social general, que respondan a las características y elementos particulares de las necesidades específicas de las víctimas individual y colectivamente consideradas y su otorgamiento se encuentre acompañado de formas de reparación simbólica y del reconocimiento del daño, estas podrán considerarse como prestaciones complementarias a las medidas generales de reparación integral.

Artículo 33.- Reparación transformadora. El Estado garantizará la reparación integral para el pueblo Rom o Gitano con carácter transformador. La reparación integral, en tanto transformadora, no se limita al resarcimiento del daño material y espiritual, o al restablecimiento de la situación anterior al hecho victimizante, sino que también se verá complementada por acciones que contribuyan a la eliminación de los esquemas de discriminación y marginación que pudieron ser la causa de los hechos victimizantes.

Artículo 46.- Reparación integral. Las víctimas a las que se refiere el artículo 30 del presente Decreto, tienen derecho a ser reparadas integralmente de manera adecuada, transfor madora, diferenciada y efectiva por el daño que han sufrido como consecuencia de los hechos victimizantes.

Del mismo modo, el Decreto - Ley 4635 de 2011, hace referencia al término "transformadora" en varios de sus artículos. 
Artículo 34.- Distinción entre las medidas de reparación y otras obligaciones del Estado. Las comunidades víctimas tienen derecho a ser reparadas de manera integral, adecuada, diferenciada, transformadora y efectiva. La ayuda y asistencia humanitarias, así como la prestación de los servicios sociales del Estado, no constituyen medidas de reparación integral. El acceso prioritario, especial y preferente de las víctimas a los servicios sociales del Estado, conforme a la Ley 418 de 1997, hace parte de la asistencia humanitaria. En consecuencia, el valor de estas medidas no podrá descontarse del valor de la reparación integral, administrativa o judicial, a la que tienen derecho las víctimas.

Artículo 38.- Reparación integral. Las víctimas a las que se refiere el artículo 30 del presente decreto, tienen derecho a ser reparadas de manera adecuada, transformadora, diferenciada y efectiva por el daño que han sufrido como consecuencia de los hechos victimizantes.

Artículo 77-. Objetivos del PIRC. Constituyen objetivos del Plan Integral de Reparación Colectiva:

\section{$[\ldots]$}

d) Contribuir de manera transformadora a la recuperación de las condiciones, capacidades y oportunidades de desarrollo personal y colectivo perdidas como consecuencia del conflicto armado;

\section{$[\ldots]$}

f) Transformar las condiciones de discriminación histórica que permitieron o facilitaron la comisión de las violaciones de que trata el artículo 30 contra las comunidades. 
Artículo 79.- Reparación integral. La reparación de las víctimas de que trata el presente decreto implica la adopción de las medidas de restitución, indemnización, rehabilitación, satisfacción y garantías de no repetición justas, adecuadas, transformadoras, diferenciadas y efectivas, en sus dimensiones individual y colectiva, material, moral y simbólica.

Por su parte, la reparación de sujetos colectivos étnica y culturalmente diferenciados como consecuencia de la ocurrencia de un daño colectivo, o un daño individual con efectos colectivos, se definirá a través de un Plan Integral de Reparación Colectiva -PIRC-, el cual será concertado con cada comunidad y sus autoridades representativas respetando su identidad étnico cultural particular y teniendo en cuenta la dimensión colectiva, étnica, cultural y ecológica de las violaciones sufridas.

Es prudente advertir que esta normativa debe interpretarse y entenderse de conformidad con las facultades que le fueron otorgadas al Gobierno Nacional en el Literal a. del Artículo 205 de la Ley 1448 de 2011, en el sentido que la misma obedece a la generación de un marco de políticas públicas el cual comprende acciones adicionales por parte del Estado encaminadas a promover la prosperidad general de los colombianos conforme a los fines que le fueron encomendados por el Artículo 2 de la Constitución Política; lo anterior, en concordancia con las consideraciones del mismo Decreto - Ley.

Tal situación se evidencia cuando la normativa referenciada dispone que dichas acciones tienen un carácter complementario y no se descuentan de la reparación integral administrativa y judicial, lo que da a entender que no hacen parte de las mismas por ser desarrollo de políticas públicas. Entonces, como expondremos más adelante, la noción de reparación adquiere otro sig- 
nificado en los programas de cubrimiento masivo de reparaciones, concebidos en el desarrollo de políticas públicas. El Decreto 4800 de 2011, igualmente emplea el concepto transformador y lo encontramos en sus artículos 5, 222 y 224. Observemos que este decreto, en desarrollo de dicha ley, actúa como complemento a la reparación de las víctimas en sede judicial, mediante la implementación de un programa masivo de reparaciones.

Artículo 5.- Enfoque transformador. Las medidas de reparación contenidas en el presente decreto buscan contribuir a la eliminación de los esquemas de discriminación y marginación que contribuyeron a la victimización, bajo el entendido que transformando dichas condiciones se evita la repetición de los hechos y se sientan las bases para la reconciliación en el país.

El enfoque transformador orienta las acciones y medidas contenidas en el presente decreto hacia la profundización de la democracia y el fortalecimiento de las capacidades de las personas, comunidades e instituciones para su interrelación en el marco de la recuperación de la confianza ciudadana en las instituciones. Asimismo las orienta a la recuperación o reconstrucción de un proyecto de vida digno y estable de las víctimas.

Artículo 222.- Reparación colectiva.

$[\ldots]$

Parágrafo.- La reparación colectiva tendrá un enfoque transformador y diferencial en tanto propenda por eliminar los esquemas de discriminación y marginación de los sujetos colectivos, que pudieron contribuir a la ocurrencia de los hechos victimizantes. 
Artículo 224.- Creación del Programa de Reparación Colectiva. Créase el Programa de Reparación Colectiva el cual será implementado y coordinado por la Unidad Administrativa Especial para la Atención y Reparación Integral a las Víctimas a través de las fases y componentes establecidos en el presente capítulo de acuerdo a los siguientes criterios establecidos en las recomendaciones del Programa Institucional de Reparación Colectiva de la Comisión Nacional de Reparación y Reconciliación:

\section{$[\ldots]$}

6. Transformación de las condiciones que pudieron generar las violaciones de derechos.

El Programa de Reparación Colectiva estará conformado por medidas de restitución, indemnización, rehabilitación, satisfacción y garantías de no repetición en los componentes político, material y simbólico. Estas medidas del Programa se ejecutarán a través de los Planes Integrales de Reparación Colectiva realizados por cada uno de los sujetos de reparación colectiva y de acuerdo con los componentes del Programa de Reparación Colectiva.

Se deduce, que el Decreto 4800 de 2011 también es un instrumento de política pública que consagra un programa masivo de reparaciones, por tal razón, el uso de la noción de reparación transformadora debe entenderse con el alcance propio de esta clase de programas.

En suma, se observa que las 'reparaciones transformadoras' en el sentido mencionado por Uprimny y Saffon (2009), no encuentran sustento en el ordenamiento jurídico colombiano. 
Ahora bien, desde nuestra perspectiva, estas serían algunas posibles consecuencias derivadas de las reparaciones transformadoras:

Dado que la responsabilidad, en su función resarcitoria, está instituida para reparar el daño y nada más que el daño, la medida y forma de la reparación están determinadas y limitadas por el mismo, es decir, por las consecuencias lesivas a los intereses jurídicos de la víctima. En consecuencia, al juez en ejercicio de la función que le fue encomendada por la Constitución de administrar justicia, le corresponde restablecer el equilibrio vulnerado por los efectos nocivos del daño. Lo anterior, sin generar un empobrecimiento ni un enriquecimiento para la víctima.

La 'reparación transformadora' al ir más allá de la restitución podría dar lugar al enriquecimiento de la víctima.

Si bien es cierto que la reparación, entendida como 'reparación transformadora', podría encontrar fundamento en la CortelDH, sentencia caso González y otras ("Campo Algodonero" V.S. México 2009). La reparación así concebida no ha sido la razón de la decisión de las sentencias de este órgano judicial. Además, hasta la fecha tampoco ha ordenado medidas resarcitorias en este sentido. Por el contrario, la CortelDH es clara al establecer que las reparaciones no pueden conllevar a un enriquecimiento de la víctima. Con base en los Artículos y Decretos citados, hemos considerado una última "posible consecuencia": el concepto de 'reparaciones transformadoras' podría dar lugar a que el juez se extralimite en el ejercicio de sus competencias e invada la órbita de facultades de otras ramas del poder público como lo es la ejecutiva. Dicha situación puede presentarse en el caso que ordene medidas relacionadas con la adopción de políticas públicas por parte del Estado, pues, insistimos esta no es una facultad propia del ejercicio de administrar justicia. 


\section{La reparación en los programas de cubrimiento masivo}

En este contexto el término 'reparar' es entendido como los esfuerzos de un Estado por dar beneficios a las víctimas de cierta clase de crímenes. Es por ello que los programas no consagran la verdad, la justicia penal o la reforma institucional como parte de las reparaciones, aunque si se busca, con la reparación, el reconocimiento, la confianza cívica y solidaridad social (De Greiff, 2006). A pesar de ello, se considera que los programas de cubrimiento masivos no pueden acoger el criterio de reparación de las víctimas en proporción al daño sufrido y esto se pone de manifiesto ya que, actualmente, ningún programa postconflicto ha conseguido tal objetivo pues la cuantificación de los daños, además de resultar problemática, genera expectativas irrealizables.

A esto se suma que los trámites para que las víctimas, caso por caso, obtengan reparación, presentan varias dificultades: desunen a las mismas debido al dispar acceso a la administración de justicia y al contraste en las indemnizaciones; vuelven vanos los esfuerzos de desagravio del Estado y tienden a estar descoordinados con otras medidas de reparación que son trascendentales, lo que genera frustración de sus beneficiarios.

- Reconocimiento, confianza cívica y solidaridad social:

El reconocimiento hace relación al esfuerzo institucional del Estado de aceptar que unos hechos sucedieron, que las víctimas son individuos, ciudadanos y titulares de derechos y que como personas no solo son sujeto de sus propias acciones sino también el objeto de las acciones de otros. En un Estado constitucional es importante que las personas se reconozcan no solo como individuos, sino también como ciudadanos. El reconocimiento genera condiciones bajo las cuales se restablecen los derechos de las víc- 
timas como iguales para que puedan relacionarse entre sí y con las autoridades como titulares de los mismos derechos (Asamblea General de las Naciones Unidas, 2012).

La confianza cívica conlleva la expectativa de un compromiso normativo compartido por una comunidad que se desarrolla a partir de un sentido mutuo con valores de todos. Esto implica la existencia de una clase de disposiciones entre ciudadanos que no se conocen pero que pertenecen a la misma comunidad política (De Greiff, 2006). Así descrita, la confianza es cómo las víctimas perciben el serio compromiso que adquieren el Estado y los conciudadanos de restablecer las relaciones de igualdad y respeto transgredidas con el acaecimiento del daño.

Asimismo, es la adhesión a normas y valores compartidos, de tal suerte que se estabilizan las expectativas jurídicas del agraviado. En suma, reparar en un marco de confianza, es alcanzar que las víctimas se sientan incluidas y en condiciones de igualdad en un proyecto político común: Un Estado como Colombia debe propender por crear y restaurar la confianza entre los ciudadanos.

Según De Greiff (2006), la actitud de solidaridad social es la capacidad de algunos individuos de ponerse en el lugar de otros, es el reconocimiento de la dignidad y los intereses de las víctimas por parte de aquellas personas tradicionalmente privilegiadas. Incluye decir la verdad, pues esta repara y crea un sentimiento de apoyo para con las víctimas. Es importante resaltar que la solidaridad social implica incorporar en la ley los intereses de las personas afectadas, ya que esto muestra una preocupación por su situación. Así entendida, la solidaridad social requiere una expresión institucional adecuada y efectiva, como por ejemplo, que la misma se consagre en una disposición normativa. 
Si bien, y por todo lo anterior, se justifica aplicar el concepto de reparación entendido de esta manera (dada la necesidad de resarcir perjuicios que son masivos y sistemáticos), los casos desbordan la fórmula tradicional de la reparación y en su mayoría, no solo es difícil su cuantificación, sino también la real posibilidad que tiene el Estado de asumir tan altos costos, puesto que en cuanto a políticas de finanzas estatales, existe en un ámbito de prioridades sociales que compiten entre sí. En consecuencia, en algunos casos, de acuerdo al contexto social, se ha llegado a considerar que ninguna forma de compensación individual será adecuada, y que por tal razón la política será la forma de reparación más efectiva a través de cambios estructurales y el establecimiento de una sociedad justa e igualitaria (Centro de Investigación y Educación Popular, Cinep; Berghof Research Center for Constructive Conflict Management, 2009).

En Colombia ello hace referencia a lo que se denomina política de la reparación, que consiste en que la sociedad y el Estado deben decidir la proporción del daño y el período en el que se va a reparar a las víctimas, es decir, qué recursos se destinarán a su resarcimiento (Garay \& Vargas, 2012). Los Decretos 4634 y 4800 , y los Decretos - Ley 4633 y 4635 de 2011, son un ejemplo de esta noción de reparación.

\section{Reparación en contexto}

Al tradicional criterio de restablecer a la víctima a la situación en la que se encontraba antes de la acción u omisión dañosa y resarcirla en proporción al perjuicio sufrido, se articula una nueva concepción de la reparación con un fundamento tanto normativo como político. Esta moderna visión implica que el criterio de compensación justa, entendida como el ideal que inspira las reparacio- 
nes, es decir, la plena restitución, la restauración del status quo ante, sea aplicado para resarcir un daño particular sufrido por una víctima en particulares circunstancias (De Greiff, 2006). De esta forma, reparar es un asunto de contexto, es decir, debe obedecer a lo que los individuos esperan de acuerdo a la sociedad en que vivan.

En este orden de ideas, para las víctimas, la reparación es la manifestación más evidente de los esfuerzos de un Estado porque se resarzan los perjuicios que han sufrido. Es así como el interés, el compromiso y la búsqueda de medios para alcanzar el resarcimiento efectivo de las víctimas por parte del Estado, a través de la agilización de los procesos judiciales, la expedición de normatividad y la celebración de convenios, hacen parte de la reparación. Todas estas acciones son elementos del restablecimiento del daño que las víctimas han padecido.

Particularmente en contextos de justicia transicional, la reparación adquiere la categoría de derecho fundamental de carácter complejo debido a que busca restablecer la dignidad de las víctimas en interrelación con la verdad y la justicia. No obstante, a pesar de ser fundamental no es absoluto, debido a que estos contextos se caracterizan por la escasez de recursos, donde resulta necesario realizar concesiones con miras a lograr la paz y la reconciliación; limitaciones que no pueden constituir su afectación excesiva (Sentencia C-753 de 2013).

Jurídicamente, en el ámbito del derecho internacional, el término reparación es empleado en un sentido amplio: todas aquellas medidas que pueden adoptarse para resarcir los diversos tipos de daños padecidos por las víctimas. Tal uso se evidencia cuando se consagran diferentes formas de reparación como la restitución, la compensación, la rehabilitación, la satisfacción y las garantías de no repetición (De Greiff, 2006). 
En este sentido, la reparación es restablecer a la víctima a su status quo ante, y compensar los daños sufridos, proveer atención social, médica, psicológica y el cese de las violaciones.

Recapitulando, la reparación en contexto debe atender a las condiciones específicas de cada víctima y a las realidades en las que se encontraba al momento del acaecimiento del daño. Por ello, adquieren especial relevancia las formas de reparación no pecuniarias, que han de obedecer a la manera cómo el daño irradia sus efectos nocivos en la órbita material e inmaterial de quien lo padece. Todo lo anterior debe ser contemplado por quien aplique la norma en cada caso concreto sin perder de vista que ha de evitar el enriquecimiento o empobrecimiento de la víctima.

\section{Una aproximación al concepto de reparación integral}

Extrayendo los elementos comunes de lo expuesto hasta el momento, volveremos a la definición del Diccionario de la lengua española (2014):

Reparación: proviene del lat. tardío reparatio-onis 'restablecimiento, renovación'.

1. f. Acción y efecto de reparar algo roto o estropeado.

2. f. Desagravio, satisfacción completa de una ofensa, daño o injuria.

Segundo, consideramos que la reparación es la finalidad última de la responsabilidad: es la prestación de dar, hacer -o no hacerobjeto de la obligación que surge de la declaratoria de responsabilidad impuesta al sujeto que en la violación de un interés jurídico 
ocasiona un daño. De allí surge el deber de componer, enmendar, colocar al perjudicado en el estado que se encontraba antes del acaecimiento del daño, dejándolo indemne o en la situación más próxima que existiría de no haber ocurrido el mismo. La reparación debe responder al impacto real del daño en la vida de la víctima, lo que conlleva a reintegrar el interés lesionado, compensar los perjuicios sufridos y proveer atención médica, social y psicológica; es cesar y garantizar la no repetición del daño.

Lo anterior plantea nuevos retos ya que, debido a las particularidades que presentan las víctimas, existe la necesidad de una reparación en contexto, es decir, de acuerdo a las especiales circunstancias de cada individuo que haya padecido un daño. Así las cosas, adquiere suma relevancia una adecuada identificación y evaluación de las condiciones de cada país para establecer, de forma certera, contextualizada y específica, las medidas de reparación.

\section{Conclusiones}

En sus antecedentes históricos, la reparación surge como una consecuencia derivada de la responsabilidad civil y penal, que en sus inicios se hallaban fusionadas y por ende, se manifestó con penas que iban desde lo corporal hasta el pago de una suma de dinero a título de resarcimiento, pasando por sanciones pecuniarias y la posibilidad de dar aquello que causó el daño.

Tradicionalmente, el concepto de reparación está dado por del deber de resarcir impuesto al responsable de un daño causado contra derecho que conlleva a ubicar al perjudicado en la situación más próxima previa al acaecimiento del daño. En este orden de ideas, la reparación surge del vínculo obligacional que se origina por la ocur- 
rencia de un daño que le es imputable a quien es encontrado responsable, y por ende, es concedida en proporción al daño sufrido. La cualificación como integral de la reparación no la desliga de ser una consecuencia derivada de la obligación de resarcir el daño por parte de quien es declarado responsable, solo que en virtud de la integralidad insta a que se realice en su totalidad desde el punto de vista del quantum del perjuicio y el tipo de daños resarcibles.

En los programas de cubrimiento masivo el alcance de la reparación obedece a los esfuerzos de un Estado por dar beneficios a las víctimas de cierta clase de crímenes. Por tal razón, en ese escenario la reparación es reconocimiento, confianza cívica y solidaridad social (De Greiff, 2006) y, en consecuencia, desde esta perspectiva, no se aplica el criterio de reparación en proporción al daño sufrido.

La redefinición de reparación plantea nuevos desafíos pues se deben contemplar el contexto social y particular de la víctima. Se pone de manifiesto la necesidad de una reparación de acuerdo con las circunstancias específicas de cada individuo que haya padecido un daño y una adecuada identificación y evaluación de las condiciones de cada país.

En la actualidad, a la noción de reparación se le otorgan diversas interpretaciones y dependen de la forma y del ámbito de aplicación en que sea utilizada. Por tal razón es significativo identificar de qué manera es empleada, para comprender su alcance y los efectos que de ello se deriva, en especial para el operador judicial a quien le corresponde aplicar el derecho. 


\section{Referencias}

Acevedo Jaramillo y otros Vs. Perú (2006, febrero 7). Excepciones Preliminares, Fondo, Reparaciones y Costas, Serie C No. 144. Corte Interamericana de Derechos Humanos.

Alpa, G. (2006). Nuevo tratado de responsabilidad civil. Lima: Juristas Editores.

Alterini, A. A., \& López-Cabana, R. (1995). Responsabilidad Civil. Medellín: Biblioteca Jurídica Diké.

Andreu, F., Antkowiak, T., Ayala, C., Beloff, M., Bertoni, E., Caballero, J. L., \& Zelada, C. J. (2014). Convención Americana sobre Derechos Humanos (C. Steiner \& P. Uribe, Eds.) Bogotá: Editorial Temis y Konrad Adenauer Stiftung.

Asamblea General Naciones Unidas (2012). Informe del Relator Especial sobre la pro moción de la verdad, la justicia, la reparación y las garantías de no repetición, Pablo de Greiff. Recuperado de https:// goo.gl/WF7bxV

Banacloche, J., Busto, J. M., Carrascosa, J., Fernández, R., Galán, J. C., García, J. A., \& Xiol, J. A. (2013). Derecho de daños 2013 (J. M. Guardia Ed.). Navarra: Thomson Reuters; Aranzadi.

Barros, E. (2007). Tratado de responsabilidad extracontractual. Chile: Editorial Jurídica de Chile.

Centro de Investigación y Educación Popular -[Cinep]., \& Berghof Research Center for Constructive Conflict Management. (2009). De la insurgencia a la democracia. Estudios de caso. Colombia, Sudáfrica, Irlanda del Norte, Acheh, Nepal, Sri Lanka (M. García Durán Ed.). Bogotá D.C.: Autor. 
Comisión Interamericana de Derechos Humanos -[CIDH]. (2013). Verdad, justicia y reparación: Cuarto informe sobre la situación de derechos humanos en Colombia. Recuperado de www.oas. org/es/cidh/docs/pdfs/justiciaverdad-reparacion-es.pdf

Comisión Interamericana de Derechos Humanos-[CIDH]. (2014). Derecho a la verdad en América. Recuperado de www.oas. org/es/cidh/informes/pdfs/Derecho-Verdad-es.pdf

Constitución Política (1991). Congreso de la República de Colombia.

Corte Interamericana de Derechos Humanos. (2005). La Corte Interamericana de Derechos Humanos. Un cuarto de siglo: 1979 2004. San José, Costa Rica: Autor.

Cortés, É. (2006). Constitución y responsabilidad civil. Una relación ambivalente. Revista de Derecho Privado, 11, 171-179.

Cortés, É. (2007). El daño patrimonial derivado de las lesiones a la integridad psicofísica. Notas sobre la jurisprudencia de la C.I.D.H. Revista de Derecho Privado, 1213, 307-323.

Cortés, É. (2009). Responsabilidad civil y daños a la persona. Bogotá D.C.: Universidad Externado de Colombia.

De Cupis, A. (1975). El daño. Teoría General de la Responsabilidad Civil (2 $2^{a}$ ed.). Barcelona: Bosh.

De Greiff, P. (2006). The hand book of reparations. Oxford: Oxford University Press.

Decreto 4634 de 2011. Por el cual se dictan medidas de asistencia, atención, reparación integral y restitución de tierras a las víctimas pertenecientes al pueblo Rrom o Gitano. Diario Oficial No. 48.278. Presidencia de la República, diciembre de 2011. 
Decreto 4800 de 2011. Por el cual se reglamenta la Ley 1448 de 2011 y se dictan otras disposiciones. Diario Oficial No. 48.280. Presidencia de la República, diciembre de 2011.

Decreto - Ley 4633 de 2011. Por medio del cual se dictan medidas de asistencia, atención, reparación integral y de restitución de derechos territoriales a las víctimas pertenecientes a los pueblos y comunidades indígenas. Diario Oficial No. 48.278. Presidencia de la República, diciembre de 2011.

Decreto - Ley 4635 de 2011. Por el cual se dictan medidas de asistencia, atención, reparación integral y de restitución de tierras a las víctimas pertenecientes a comunidades negras, afrocolombianas, raizales y palenqueras. Diario Oficial No. 48.278. Presidencia de la República, diciembre de 2011.

Fisher, H. A. (1928). Los daños civiles y su reparación (Trad. W. Roces) Madrid: Librería general de Victoriano Suárez.

Garay, L. J., \& Vargas, F. (2012). Memoria y reparación: elementos para una justicia transicional pro víctima. Bogotá: Universidad Externado de Colombia.

Garrido y Baigorria Vs. La República Argentina (1998, agosto 27). Reparaciones y costas, Serie C No. 39. Corte Interamericana de Derechos Humanos.

Ghersi, C. A. (1995). Modernos conceptos de responsabilidad civil. Medellín: Biblioteca Jurídica Diké.

Gil, E. (2011). Responsabilidad extracontractual del Estado (5a ed.). Bogotá: Temis S.A. 
González y otras ("Campo Algodonero") Vs. México (2009, noviembre 16). Excepción preliminar, fondo, reparaciones y costas, Serie C No. 205. Corte Interamericana de Derechos Humanos.

Gual, J. M. (2009). Cláusulas de exoneración y limitación de responsabilidad civil. Bogotá: Grupo Editorial Ibáñez.

Henao, J. C. (2007). El Daño. Análisis comparativo de la responsabilidad extracontractual del Estado en el derecho colombiano y francés (2da ed.). Bogotá: Universidad Externado de Colombia.

Henao, J. C. (2015). Las formas de reparación en la responsabilidad del Estado: hacia su unificación sustancial en todas las acciones contra el Estado. Revista de Derecho Privado, 28, 277-366.

Jalil, J.E.(2013). Derecho de daños aplicado. Bogotá: Grupo Editorial Ibáñez.

Koteich, M. (2006). El daño extrapatrimonial, las categorías y su resarcimiento. Revista de Derecho Privado, 10, 161-193.

Koteich, M. (2012). La reparación del daño como mecanismo de tutela a la persona. Del daño a la salud a los nuevos daños extrapatrimoniales. Bogotá: Universidad Externado de Colombia.

Lanni, S. (2013). La reelaboración de la responsabilidad civil: nuevos códigos civiles y diálogo euro-latinoamericano. Revista de Derecho Privado, 25, 219-234.

Ley 975 de 2005. Por la cual se dictan disposiciones para la reincorporación de miembros de grupos armados organizados al margen de la ley, que contribuyan de manera efectiva a la consecución de la paz nacional y se dictan otras disposiciones para acuerdos humanitarios. Diario oficial No. 45.980. Congreso de la República de Colombia, junio de 2011. 
Ley 1448 de 2011. Por la cual se dictan medidas de atención, asistencia y reparación integral a las víctimas del conflicto armado interno y se dictan otras disposiciones. Diario oficial No. 48.096. Congreso de la República de Colombia, junio de 2011.

Mazeaud, H., Mazeaud, L., \& Tunc, A. (1977). Tratado teórico de la responsabilidad civil delictual y contractual (Vol. 1, 5ta ed.). Buenos Aires: Ediciones Jurídicas Europa - América.

Molinas, J. (Ed.). (1889). Cuerpo del derecho civil romano. Primera parte. Instituta - Digesto (Trad. D. I. García del Corral) Barcelona: Consejo de Ciento.

Navia, F. (2006). La responsabilidad extracontractual del Estado a la luz del artículo 90 de la Constitución Política. Revista de Derecho Privado, 6, 213-231.

Olano, H. A. (2013). El trámite legal para el pago de obligaciones pecuniarias impuestas al Estado colombiano en decisiones sobre derechos humanos y derecho internacional humanitario. Boletín Mexicano de Derecho Comparado, 46(137), 529-571.

Real Academia Española (2014). Diccionario de la lengua española (23a ed.). Recuperado de http://dle.rae.es/?id=WODqCv J

República Francesa. Ley del 21 de marzo de 1804. Código civil francés. Impresión de la República, marzo de 1804. Recuperado de http:// gallica.bnf.fr/ark:/12148/bpt6k1061517

Resolución 60/147 de 2005. Principios y directrices básicos sobre el derecho de las víctimas de violaciones manifiestas de las normas internacionales de derechos humanos y de violaciones graves del derecho internacional humanitario a interponer recursos y obtener reparaciones. Asamblea General de la Organización de las Naciones Unidas, diciembre de 2005. 
Restrepo, T. (2008). El remedio preventivo de la responsabilidad civil. Revista de Derecho Privado, 14, 221-238.

Sánchez, L. C. (2012). Reflexiones en torno a las funciones de la condena por daños extrapatrimoniales a la persona a partir del estudio de la "iniuria" del derecho romano clásico. Revista de Derecho Privado, 23, 333-376.

Sarmiento, M. G. (2009). Estudios de responsabilidad civil (2da ed.). Bogotá D.C.: Universidad Externado de Colombia.

Sentencia C-753 (2013, octubre 30). Acción de inconstitucionalidad. M.P. Mauricio González Cuervo. Corte Constitucional.

Sentencia del 14 de septiembre de 2011. Radicación número. (Consejo de Estado. Sala de lo Contencioso Administrativo. Sección Tercera. Radicación número: 0500123-31-000-20070013901(38222). C.P. Enrique Gil Botero. Consejo de Estado, Sala Plena de lo Contencioso Administrativo, Sección Tercera.

Schipani, S. (2007). De la Ley Aquilia a Digesto 9. Perspectivas sistemáticas del derecho romano y problemas de la responsabilidad extracontractual. Revista de Derecho Privado, 12-13, 263-287.

Solarte, A. (2009). Principio de la reparación integral del daño en el derecho contemporáneo. En M. Bernal, C. I. Jaramillo, M. López, A. Solarte, J. Arrubla, J. Oviedo, \& E. Gil (Ed.s), Tendencias de la responsabilidad civil en el siglo XXI (Vol. 1, pp. 121155). Bogotá D.C.: Pontificia Universidad Javeriana; Biblioteca Jurídica Diké.

Tamayo, J. (2007). Tratado de responsabilidad civil. Bogotá D.C.: Legis Editores S.A. 
Torres, A. (1998). La reparación del daño en la práctica de la Corte Interamericana de Derechos Humanos. Revista de Derecho Privado, 4, 151 - 175.

Uprimny, R., \& Saffon, M. P. (2009). Reparaciones transformadoras, justicia restaurativa y profundización democrática. En C. Díaz, N. Sánchez \& R. Uprimny (Eds.), Reparar en Colombia: Ios dilemas en contextos de conflicto, pobreza y exclusión (pp. 67-144). Centro Internacional para la Justicia Transicional -[ICTJ] y Centro de Estudios de Derecho, Justicia y Sociedad -[DeJuSticia].

Velásquez, O. (2009). Responsabilidad civil extracontractual. Bogotá D.C.: Temis.

Viney, G. (2007). Tratado de derecho civil. Introducción a la responsabilidad. Bogotá D.C.: Universidad Externado de Colombia.

Viney, G., \& Jourdain, P. (2001). Traite de droit civil: les effets de la responsabilite. Francia: Librairie Generale de Droit et de Jurisprudence; L.G.D.J.

Visintini, G. (2015). ¿Qué es la responsabilidad civil?: Fundamentos de la disciplina de los hechos ilícitos y del incumplimiento contractual (Trad. M. Cellurale). Bogotá: Universidad Externado de Colombia.

Yágüez, R. d. (1993). Tratado de responsabilidad civil (3ra ed.). Madrid: Editorial Civitas S.A. 